\title{
Review of Paediatrics In-Patient at Nepal Medical College and Teaching Hospital
}

\author{
Upadhyay $\mathbf{S}^{1}$, Sharma $A^{2}$, Rijal $\mathbf{P}^{3}$, Shrestha $\mathbf{S}^{4}$ \\ ${ }^{1}$ Dr. Satyam Upadhyay, MBBS, MD, Lecturer, ${ }^{2}$ Dr. Anya Sharma, MBBS, MD, Lecturer, ${ }^{3}$ Dr. Prashant Rijal, MBBS, \\ MD, Lecturer, ${ }^{4} \mathrm{Dr}$. Sabina Shrestha, MBBS, MD, Lecturer. All from Department of Paediatrics, Nepal Medical College, \\ Jorpati, Kathmandu, Nepal
}

Address of Correspondence: Dr. Satyam Upadhyay, E-mail: satyam85@hotmail.com

\begin{abstract}
Introduction: This retrospective study was undertaken to analyze the disease pattern in the Pediatric ward in a Medical College. After analyzing the data, our study would emphasize on the prevention and the management modality of the most prevalent diseases in the community. Methodology: This study was carried out retrospectively for one year from January 2008 - December 2008 on the basis of age and sex and the frequency of disease according to the system involved. Results: A total number of 453 patients were admitted during the study period. There were $267(59 \%)$ male and $186(41 \%)$ female children. Less than five years age group accounted for 180(39.7\%) excluding the neonate. In the study period, respiratory tract infections were the commonest cause of admission in all age group 198(43.7\%), gastrointestinal including diarrhoeal diseases were 112(24.7\%), enteric fever comprised of 22(5\%), and other disease comprised of about $143(31.5 \%)$ of the total admissions. CNS diseases comprised of $43(9 \%)$ of which $7(16 \%)$ were meningitis and meningoencephalitis, $26(60 \%)$ of the total CNS cases were due to febrile convulsion. Respiratory diseases were found to be the major cause of morbidity in children. Conclusion: Children under five years age being the most common age group amongst all, with infection being the most predominant cause of Pediatric morbidity, the WHO/UNICEF algorithm for Integrated Management of Childhood IIIness (IMCI) is specifically suited for the developing country like ours.
\end{abstract}

Key words: Paediatric Inpatient, Morbidity, IMCI

\section{Introduction}

$\mathrm{N}$ epal Medical College and Teaching Hospital is situated at Attarkhel, Jorpati, Kathmandu. Patients come to this hospital from various parts of Kathmandu, Lalitpur and Bhaktapur and the other neighboring districts. The main objective of the study was to determine the common disease pattern of the children seen in and around the Kathmandu valley from where they come to this hospital. After analyzing the data, our study would emphasize on the prevention and the management modality of the most prevalent diseases in the community.

The objective of the study was to find out the following,

1) Age group and sex distribution of children.

2) Types of diseases in children.
3) Common diseases found in the admitted patients.

4) Number of days of stay in the hospital.

5) Month wise record of children admitted in the hospital.

6) Geographic distribution of the patient coming to Nepal Medical College.

\section{Methods}

After obtaining consent from the Hospital Director, all inpatient record files of admitted patients in the pediatric ward were analyzed retrospectively on the basis of age and sex and the frequency of disease according to systems involved. Their addresses mentioned in the record file was noted and the number of hospital stay was calculated based on admission and discharge date. The final diagnosis was recorded. 


\section{Results}

A total no of 453 patients were admitted during the study period. Males were $267(59 \%)$ and females were $186(41 \%)$. Less than five years age group accounted for $180(39.7 \%)$ excluding the neonates [Fig.4]. In the study period, respiratory infections were 198(43.7\%), gastrointestinal including diarrhoeal diseases were $112(24.7 \%)$ of which Enteric fever comprised of 22(5\%), and other diseases comprised of about 143(31.3\%) amongst the total admissions. Respiratory tract infections were the commonest cause of admissions in all age group. Other than respiratory and gastrointestinal, the most common condition was febrile seizure constituting $26(6 \%)$ of total admissions. The CNS diseases comprised of $43(9 \%)$ of total admissions out of which $7(16 \%)$ were meningitis and meningoencephalitis. $26(60 \%)$ of total CNS cases were febrile convulsions.
The highest number $42(21.2 \%)$ of respiratory diseases were admitted in September followed by 27(13.6\%) in August and 18(9\%) in March [Fig.2]. Cases of diarrhoea were seen mostly during May 25 (22.3\%) and July $16(14.2 \%)$ showing that the admission rate of diarrhoeal diseases were higher during the rainy season. Sporadic cases of cholera were seen in July $(n=1)$, August $(n=2)$ and September $(n=1)$.

The month of May 68 (15\%) and July 56 (12.3\%) was found to have the highest number of admission and November 16 (3.5\%) and December 16 (3.5\%) the lowest [Fig.3].

Geographically maximum number of patients came from Jorpati 334 (74\%) and the rest from other places.

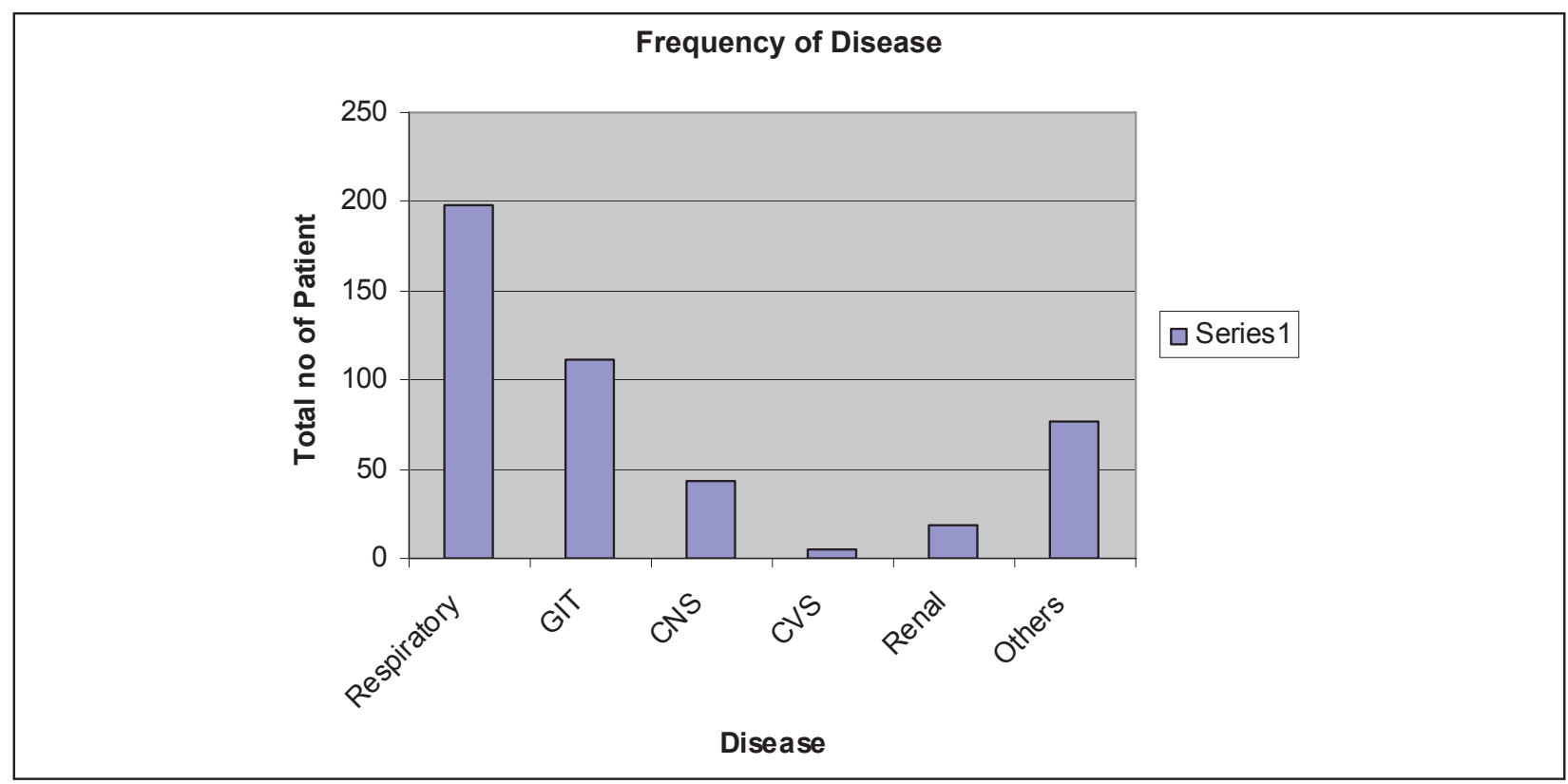

Fig 1: Showing System wise Frequency of Diseases.

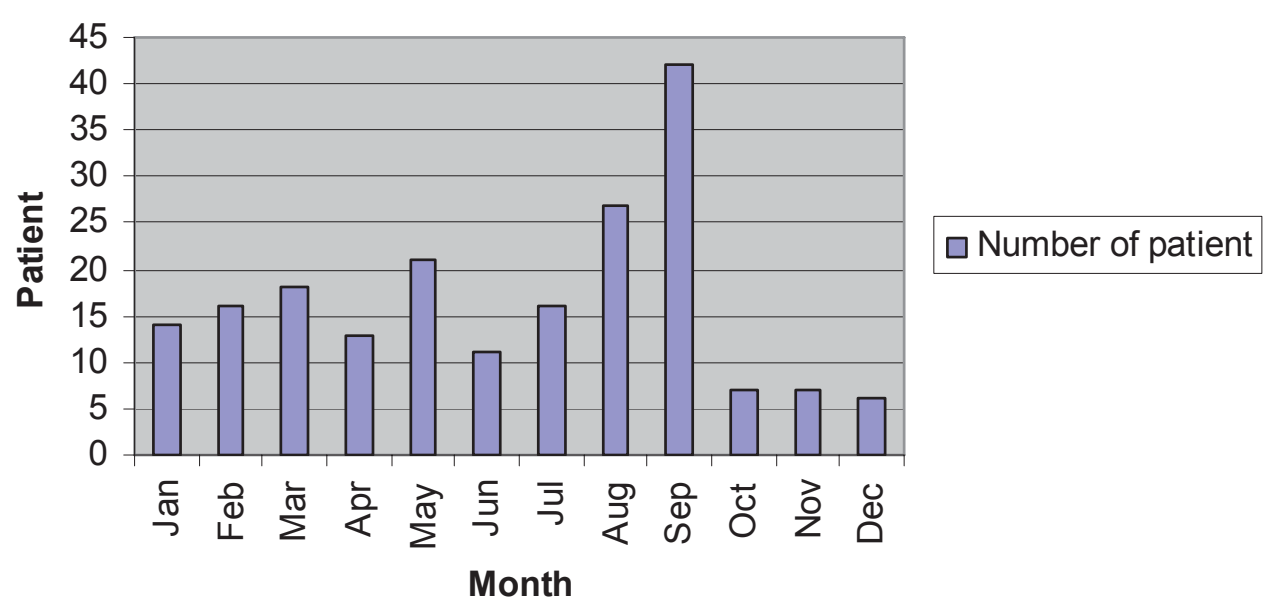

Fig 2: Graph showing Frequency of Respiratory Diseases. 


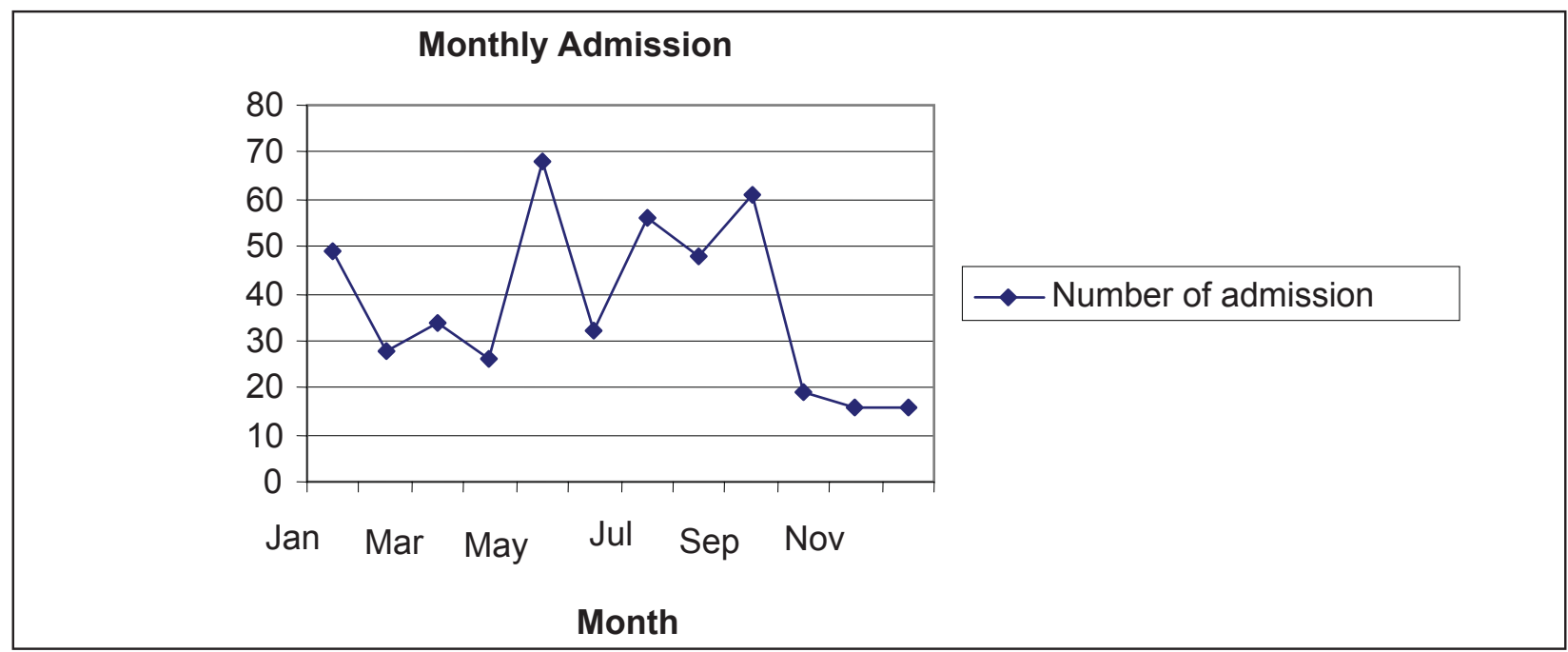

Fig 3: Line diagram showing seasonal trend in admissions (total).

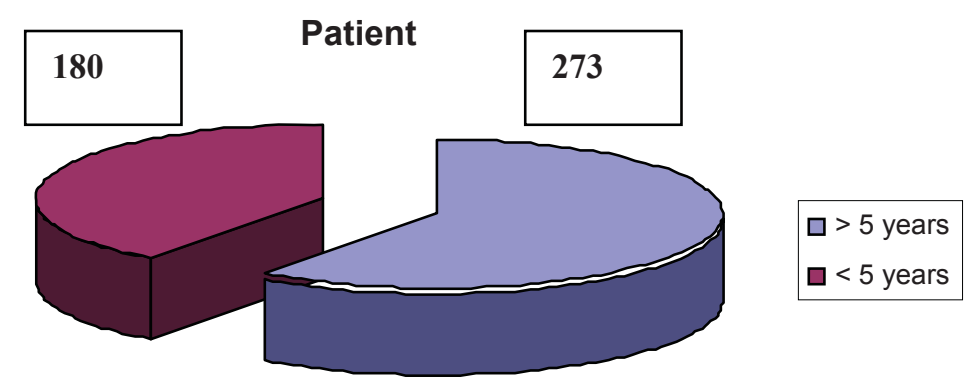

Fig 4: Total number of Admissions according to the age group.

Table 1: Showing days of stay in Hospital

\begin{tabular}{|c|c|}
\hline No of patient & Duration of Hospital stay \\
\hline 158 & 4 days \\
\hline 78 & 5 days \\
\hline 80 & $>6$ days \\
\hline & \\
\hline
\end{tabular}

\section{Discussion}

\section{Age and sex distribution}

In the study period, among 453 admitted children, $267(59 \%)$ were males and $186(41 \%)$ were females. The male and female ratio was $\mathrm{M}: \mathrm{F}=1.43$ lower than $(1.67)^{1}$ and $(1.78)^{2}$ that was obtained in the study conducted among 761 and 312 patients in Kathmandu Medical College Teaching hospital (KMCTH) and Dhulikhel Hospital (Kathmandu University Teaching Hospital) respectively. Less than five years age patients admitted in the pediatric ward were $180(39.7 \%)$ of the total number of admissions. The least number of admitted patients were the age of more than 12 .

\section{Pattern of Disease}

In the study period, 198 (43\%) of the diseases comprised of respiratory tract infections including Pneumonia, Acute Bronchiolitis and wheezy chest. Acute Gastroenteritis comprised of 112 (24.7\%). Tuberculosis comprised of $19(4.1 \%)$ of the admitted cases that was comparatively more than in the studies done in KMCTH $(2.4 \%)^{1}$ among 489 patient and in Dhulikhel Hospital $(3.2 \%)^{2}$ of 312 patients. These figures were statistically low in all three studies in our country as compared to the study done by Hauser WA ${ }^{3}$ which vary between $15 \%$ in developing countries and below $5 \%$ in the United States and European Countries. The low incidence in our studies could be due to difficulty in estimating the 
TB burden in children. Challenges for doing so include difficulties in establishing a definitive diagnosis, the increased presence of extrapulmonary disease in young children, the lack of standard definition, and the low priority on the public health agenda compared to adult TB. ${ }^{4}$ Lack of education, poor socioeconomic status, lack of health awareness and the belief in traditional healers were the reason for late presentation contributing to the morbidity and mortality due to the diseases.

Febrile convulsions were seen in $5.7 \%$ of the total cases and in $26(60 \%)$ of the CNS diseases which was higher than the study conducted in $\mathrm{KMCTH}(50 \%)^{1}$ and Dhulikhel Hospital $(48.27 \%)^{2}$. Worldwide cumulative incidence of febrile convulsion among children ranges from about $1 \%$ in China to more than $8 \%$ in Japan ${ }^{5}$. Meningitis was seen in $8(1.7 \%)$ out of which one was Meningococcal Meningitis. Aseptic Meningitis secondary to mumps was also seen. Out of 18 (4\%) renal cases, 6 (33\%) were Nephrotic Syndrome and $7(38 \%)$ were Nephritic Syndrome. The low incidence of childhood renal diseases in our study could be because renal diseases in children are commonly associated with few or no symptoms ${ }^{6}$. Out of $7(1.5 \%)$ Cardiac patients 2 cases were Constrictive Pericarditis and 5 cases of Acute Rheumatic Fever were also admitted out of which 2 cases presented with only Chorea as the sole manifestation of Acute Rheumatic Fever. Majority of the cardiac patients were of Rheumatic origin and this is attributed to the poor socioeconomic status leading to unhygienic living conditions and overcrowded households that predisposes to the spread of Streptococcal infections and poor and under-nutrition of our patients that alter the immunological response in increasing the susceptibility to infections ${ }^{7} .2$ cases of Kerosene Poisoning, 2 cases of ITP, 3 cases of HSP, a case of Congenital Hypothyroidism, a case of Kalazar were also admitted during this period.

Among the respiratory cases, most were Pneumonia followed by Acute Bronchiolitis. Acute Bronchiolitis were admitted mainly during the winter season, this might have been due to seasonal outbreak of respiratory viral infection particularly respiratory syncytial virus and influenza viruses ${ }^{8}$. Diarrhoeal diseases were mostly seen during rainy season ${ }^{9} 19(4.1 \%)$ of the total cases. Sporadic cases of cholera were seen in July (1), August (2) and September (1) similar to the study done in Karachi, Pakistan by Sheikh et.al published in 1997 in which the Cholera cases peaked during April to October $^{10}$.

\section{Days of Stay in Hospital}

In the study period, it was seen that maximum number of patient i.e. 158 (34.8\%) stayed for 4 days followed by $80(17.6 \%)$ for 5 days. Patients staying 6 days or more were $78(17.2 \%)$.Table:1 Patients with complication of Pneumonia, Meningitis, and Nephritic Syndrome were found to have longer duration of stay.

\section{Geographic Distribution of In -Patient Admissions}

In the study period, the maximum number of patient came from Jorpati 334 (74\%) and the rest from the neighboring districts namely Bhaktapur, Lalitpur, Kavre and Ramechhap.

\section{Monthly Admissions}

In the study period, the highest number of admission was $68(15 \%)$ in May and the lowest was $16(3.5 \%)$ in December.Fig. 3 . This may be because of increased number of diarrhoeal disease and respiratory disease during this season. The number of admission in the rest of the month were as follows, January 49 (10.8\%), February 28 (6.1\%), March 34 (7.5\%), April $26(5.7 \%)$, June $32(7 \%)$, July 56 (12.3\%),August 48 (10.5\%), September 61(13.4\%) October $19(4.1 \%)$ and November 16 (3.5\%).

\section{Conclusion}

Children under five being the most common age group amongst all, with infection being the most predominant cause of Pediatric morbidity, the $\mathrm{WHO} /$ UNICEF algorithm for Integrated Management of Childhood Illness (IMCI) is specifically suited for the Hospital setup like ours.

\section{Acknowledgements}

I would like to thank Mr Rishi Sapkota of the medical record section who has helped with data collection.

Funding: None

Conflict of interest: None

Permission from IRB: Yes

\section{References}

1. Bajracharya BL, Joshi $P$, Manandhar DS, Baral MR. Review of Paediatrics Inpatient At Kathmandu Medical College. J Kath Med Col 2002;4:43-49

2. Nepali N, Ghimire R, Shrestha RPBS. Review of Paediatrics Inpatient at Dulikhel Hospital, Kathmandu University Teaching Hospital. J Nepal Paedtr Soc 2007;26:16-19

3. Murray CJ, Styblo K, Rouillon A,TB in developing countries:burden,intervention and cost. Bull Int Union Tuberc Lung Dis 1990;65(1):6-24 
4. Cooreman E. Global epidemiology of Pediatric Tuberculosis. In:Seth V,Kabra SK. Essentials of Tuberculosis in children, $3^{\text {rd }}$ Ed,Jaypee;2006.p.11

5. Hauser WA, The prevalence and incidence of convulsive disorder in children. Accessed Nov 2010, Available from http://www.ncbi.nlm.nih.gov/ pubmed/8275976

6. Michael IO, Ofili AN.Childhood Renal Diseases In Benin-City:Assessment Of Knowledge And Practices Among General Medical Practcioners. Tropical J Health Sci 2005;12(1):31-35

7. Tandon R, Rheumatic Heart Disease.In: Ghai O.P, Gupta P, Paul V.K, Essential Pediatrics, $6^{\text {th }}$ Ed,New Delhi, CBS publishers;2004.p.375
8. Chew F.T Doraisingham S, LingA.E, Kumarrasingha G, Lee B W. Seasonal Trends of Viral Respiratory Tract Infection In the Tropics. Epidemiol Infect 1998;121:121-128

9. Mohapatra S C,Mohapatra P,Singh IJ,Gaur SD. Epidemilogy of gastrointestinal and Respiratory tract Disease in a rural areas of Varanasi (India). Eur J of Epid 1989; 5(1):117-122.

10. Sheikh A, Khan A, Malik T Fisher-Hoch SP,Cholera In Developing Megacity, Karachi, Pakistan. Epidemiol Infect 1997;119(3):287-292.

\section{How to cite this article?}

Upadhyay S, Sharma A, Rijal P, Shrestha S.Review of Paediatrics In-Patient at Nepal Medical College and Teaching Hospital. J Nepal Paedtr Soc 2011;31(1):25-29. 